\title{
Functional Issues in Brain Tumor Treatment
}

\author{
Hongyan Yang ${ }^{1}$, Michael Chopp ${ }^{3,4}$ and Timothy Schallert ${ }^{1,2,3 *}$
}

${ }^{1}$ Institute for Neuroscience and Department of Psychology, University of Texas at Austin, 1 University Station, \#A8000, Austin, TX 78712, USA

${ }^{2}$ Department of Neurosurgery, University of Michigan, Ann Arbor, MI 48109, USA

${ }^{3}$ Department of Neurology, Henry Ford Health Sciences Center, Detroit, MI 48202, USA

${ }^{4}$ Department of Physics, Oakland University, Rochester, MI 48309, USA

\begin{abstract}
The limited success of current treatment options that attempt to shrink brain tumors, along with the accompanying compromised quality of remaining life, raise increasing concerns about the adverse effects of cancer treatment on brain function. Some aggressive cancer treatments can directly damage normal brain tissue that surrounds the tumor, while other regulatory paradigms may harm neuroplastic mechanisms which are important in functional recovery. Functional outcome is a major target in clinical trials, but seems to be neglected in translational brain tumor research. Some recent research has started to fill the critical behavioral void in this field. Optimal treatment strategies would cure the disease and save life without reducing the integrity of the brain. Furthermore, neurorehabilitative treatments are needed to repair the damage caused by not only brain tumors but also conventional cancer treatment approaches.
\end{abstract}

Keywords: Brain tumor; Behavioral measurement; Neuroplasticity; Recovery of function; Quality of life

\section{Introduction}

In 2000 , it was estimated that 16,500 new cases of primary brain tumors would occur in the United States, with 13,000 deaths [1]. Although brain tumors constitute only a small proportion (about 1.4 percent) of overall human malignancies, they carry high rates of morbidity and mortality. More terrifyingly, brain tumors often strike young people. Central nervous system neoplasm is the second most common type of childhood malignancy (after leukemia) and the second leading cause of cancer deaths in children [1]. Furthermore, brain tumors are among the most devastating to patients, because they affect an irreplaceable organ that fundamentally defines each individual's uniqueness.

\section{Brain Tumor Treatments and Their Impacts on Brain Function}

Conventional brain tumor treatments include surgery, radiation therapy and chemotherapy. Surgery is generally the first step and the most effective treatment for reducing tumor size as well as brain pressure for both malignant and non-malignant brain tumors. Radiation therapy plays a central role in the management of malignant tumors. Radiation therapy plus surgery has been shown to extend the life expectancy of patients with malignant gliomas compared with surgery alone $[2,3]$. Chemotherapy is important in the treatment of some but not all types of brain tumors in helping to extend the survival time of patients.

Although most primary brain tumors rarely metastasize, the regional infiltration into the surrounding normal tissue during tumor progression leads to badly demarcated borders and underlies their great propensity for recurrence [4]. High-grade gliomas are the most frequent primary brain tumors in adult patients. The high incidence of recurrence and poor prognosis of malignant gliomas compel the development of more powerful anti-cancer treatments. Many treatments that can shrink brain tumors may not meaningfully increase survival, and even if they increase survival, they may not necessarily improve function, at least not optimally. The compromise of the quality of remaining life as well as the limited success of current treatment options in shrinking tumors raise increasing concerns about the adverse effects of cancer treatment on brain function. Deterioration in neurological function is accompanied by significant deterioration in the global quality of life in patients with high-grade glioma [5]. In the clinic patients, the impact of radiation and chemotherapy on the quality of life has to be considered before initiating treatment, and once treatment-related neurological or cognitive deficits occur, acute and long-term neurotoxicities need to be weighed against the benefits in order to decide whether the dose should be lowered or the therapy should be terminated [6].

The following sections discuss why aggressive brain cancer treatments are not commonly implemented, and how different treatment modalities may adversely affect brain function and harm neuroplasticity.

\section{Surgery}

Surgery is the most important treatment modality that is aimed at maximal debulking of the tumor burden. However, surgery can directly damage surrounding normal brain tissue. A particular difficulty in the treatment of brain tumors, in contrast to other types of tumors, is that every brain area is specialized for certain functions. Some tumors can be removed completely, such as meningiomas and grade I gliomas, for which, surgery is curative. In general, a surgical resection as complete as possible is recommended, as long as tumor can be removed safely without leaving an unacceptable neurological deficit. However, even when all visible tumors are removed during surgery, there are still chances of local recurrence. Tumors that are in deep parts of the brain or involve critical structures, such as those that allow one to speak and understand, however, may not be even partially resectable.

*Corresponding author: : Timothy Schallert, Institute for Neuroscience, University of Texas at Austin, 1 University Station, \#A8000, Austin, TX, 78712, USA, Tel: 512 471-6141; Fax: 512-232-4335; E-mail: tschallert@mail.utexas.edu

Received July 20, 2011; Accepted December 06, 2011; Published December 20, 2011

Citation: Yang H, Chopp M, Schallert T (2011) Functional Issues in Brain Tumo Treatment. J Neurol Neurophysiol S5. doi:10.4172/2155-9562.S5-002

Copyright: ( 2011 Yang $\mathrm{H}$, et al. This is an open-access article distributed unde the terms of the Creative Commons Attribution License, which permits unrestricted use, distribution, and reproduction in any medium, provided the original author and source are credited. 


\section{Radiation therapy}

For low-grade gliomas, radiation therapy with a total dose $\leq 50$ Gy in 1.7 to 2 Gy daily fractions is usually used with the 5 -year survival rate of 50\% [7]. For high-grade gliomas, large, randomized clinical trials demonstrated that 60 Gy has a significant survival advantage over 50 Gy $[8,3]$. Thus, the standard dose for high-grade gliomas is considered to be $60 \mathrm{~Gy}$ in 30-33 fractions [7]. However, most patients show recurrence within $2.0 \mathrm{~cm}$ of the pre-surgical, initial tumor margin, implicating that current radiation doses are inadequate for treatment of the primary tumor [9-11]. No survival difference was found between limited-volume radiation and whole-brain radiation, since new intracranial metastases are always antedated by tumor progression at the primary site [12]. Even with high-dose (70 or 80 Gy) conformal irradiation, the great majority of cases still failed with central or infield recurrences, suggesting that further dose escalation to $90 \mathrm{~Gy}$ and beyond is reasonable [13]. Although local recurrence is still inevitable following high-dose radiation, central recurrence is delayed and the survival time is extended [14]. By general consensus, increasing the amount of radiation delivered to gliomas results in enhanced tumor cell death and a trend of improved survival.

However, the neurotoxicity limits further dose escalation. With standard external beam radiation, a dose of 60 Gy exceeds the threshold for toxicity $[15,16]$. The tolerance of the brain to radiation depends on the dose per fraction and the total dose applied [15]. Cranial radiation can induce some generally mild and self-limited acute complications, including increased intracranial pressure and exacerbation of preexisting neurological symptoms that are due to edema and demyelination. However, clinical studies demonstrate that chronic, potentially fatal or permanent complications can also occur and are characterized by seizure, dementia, growth failure in children and other neuropsychological impairments that are a result of direct damage to the brain and blood vessels [17-20].

Radiation therapy may harm neuro-plasticity. In animal models, low-dose radiation attenuates neurogenesis and exacerbates ischemiainduced cognitive deficits [21] and radiation-induced cognitive impairments can be detected with spatial learning tasks and are associated with a decrease in hippocampal neurogenesis [22].

\section{Chemotherapy}

Some tumors such as grade 2 and 3 gliomas require chemotherapy in addition to surgery and radiation therapy. Glioblastoma multiforme is refractory to treatment; however, chemotherapy when combined with surgery and radiation carries a small therapeutic benefit. However, chemotherapy as well as radiation is widely blamed for further neurological complications in brain tumor patients $[23,20]$. Children who were treated for supratentorial tumors had significantly more learning problems, and children who were treated for infratentorial tumors had significantly more behavioral and social problems [23].

5 -fluorouracil is a widely used and studied chemo regimen. Systemic chemotherapy with 5-fluorouracil can lead to central neurotoxicity [2430], although not common and typically subtle. Candidate mechanisms for chemotherapy-induced cognitive changes include DNA damage, telomere shortening, cytokine deregulation, and estrogen decline, which may act independently or interactively [31]. Genetic variability in blood-brain barrier transport of chemotherapy agents, DNA repair capacity, neural repair capacity and neurotransmitter regulation affects cognitive function in cancer patients after chemotherapy [31]. Impaired performance in several learning and memory tests was observed in mice receiving a combination of two anti-cancer drugs, methotrexate and $5 \mathrm{FU}$, which may be attributed to functional changes in specific brain regions, including the frontal lobes and hippocampus [32]. Normal brain cells, especially progenitor cells and oligodendrocytes, which play important roles in neural repair, are more susceptible to chemotoxicity than cancer cells, and systemic administration of chemotherapeutic agents leads to reduced cell division and increased cell death in the adult mouse brain even long after drug exposure [33].

New compounds, that demonstrate selective tumor localization and/or can increase the sensitivity of tumor cells to radiotherapy, chemotherapy, and photodynamic therapy [34-39], represent a potential future of cancer treatment.

\section{Novel experimental brain tumor treatments}

Local chemotherapy: Local chemotherapy has been actively investigated in the latest decade. Fluorouracil (5FU) has been widely used as a local chemotherapy agent. The potential reasons are, first, $5 \mathrm{FU}$ is hydrophilic, and does not readily cross the blood brain barrier (BBB). When systemically administered, 5FU has very little effect on malignant gliomas and other tumors implanted in the brain [4042]; however, it shows some effect on the same types of malignant brain tumors implanted in the flank $[43,44]$, indicating that its lack of effectiveness is due to its limited concentration inside the tumor. A direct drug delivery of chemotherapy, such as $5 \mathrm{FU}$, to the brain tumor can increase drug levels in the tumor area and can also decrease undesired systemic side effects [45-48]. Second, 5FU has relatively less direct neurotoxicity compared to other commonly used chemotherapy drugs. 5FU is an anti-metabolic drug. The mechanism of action of 5FU is associated with the incorporation of 5FU into DNA and RNA and the inhibition of nucleic acid synthesis, thus affecting actively proliferating cells [49]. A recent study in rats has shown that regional delivery of $5 \mathrm{FU}$ into the sensorimotor cortex can initiate functional impairment in a healthy brain, while following a focal cortical tissue displacement that is partly characteristic of a brain tumor, it can exaggerate secondary degeneration and impede functional recovery [50].

\section{Anti-invasive and anti-angiogenic treatments}

Regulatory paradigms, such as anti-invasive and anti-angiogenic treatments, are aimed at controlling tumor growth and spread [51]. The regulatory paradigms may not directly damage normal brain tissue, but they may harm the neuroplastic mechanisms which are important in functional recovery.

To a limited extent, the brain is capable of repairing itself after damage. Emerging data support the essential roles of neurogenesis, angiogenesis, upregulation of growth factors and inhibition of spontaneous apoptosis in recovery and restoration after stroke and other brain injuries [52-57]. However, many of the developmental and neuroplastic mechanisms might also be what brain tumors rely on to support growth, differentiation, invasion and metastasis and therefore targets of brain tumor treatments [58-62]. For example, gliomas are angiogenesis-dependent $[63,64]$. Vascular endothelial growth factor (VEGF) secreted by glioma cells plays a prime role in the induction of tumor angiogenesis [65-67]. The neutralization of endogenous VEGF suppresses the growth of gliomas $[68,69]$. However, inhibition of VEGF also impedes revascularization and neural repair after brain injury in a rat stab wound model [70]. Similarly, FGF-2 produced by some types of gliomas is related to angiogenesis and tumorigenicity [71-74]. Inhibition of basic fibroblast growth factor (FGF-2) impedes glioma growth [74]. However, blockading FGF-2 with neutralizing 
antibodies retards functional recovery following suction lesions of the motor cortex in rats [75], because FGF-2 is one of many neurotrophic factors that can enhance recovery from brain injury [76,77]. Longterm blockage of N-methyl-D-aspartate (NMDA) glutamate receptors limits glioma growth in rats by inhibiting proliferation and migration of tumor cells as well as inducing tumor cell death [78-80]. However, after a delay, this drug can adversely reverse functional recovery in rats with compressive mass injury to the sensorimotor cortex [81], possibly because glutamatergic activity at NMDA receptors may be involved in chronically maintaining neural adaptations linked to restoration of function [82].

\section{Can a Brain Tumor Induce Neuroplasticity?}

Tumor-induced brain damage is characterized by various injury patterns, such as cerebral ischemia, mechanical compression, denervation, and excitotoxicity, all of which can trigger brain plasticity [54,83-88,57,89-91,81,92,50,93-96] that likely fosters functional recovery $[53,55]$. The relatively slow growth pattern of brain tumors makes the brain's responses to them likely to be similar to the gradual adaptive mechanisms observed in progressive neurodegenerative diseases [97], and prevents early diagnosis. Recent studies have shown neurogenic responses of the subventricular zone (SVZ) to malignant brain tumors grown in the striatum $[98,99,100]$, as well as reactive peritumoral plasticity-related changes, including synaptogenesis, astrocyte activation and angiogenesis [101], suggesting that a brain tumor, like other lesion types, is able to elicit neuroplasticity. The peri-tumoral and/ or remotely located mechanisms of brain plasticity may continuously compensate for tumor-associated insult, potentially contributing to the stealth nature of brain tumors.

\section{Neurorehabilitative Treatments are Needed in Brain Tumor Management}

Neurorehabilitative treatments may be helpful in repairing the damage caused by brain tumors themselves and the neurological impairment that is frequently associated with conventional approaches to cancer treatment. An increase in the intensity of aggressive cancer therapies may be allowed by the availability of neurorestorative regimens, which might keep the neurological side effects at a tolerable level, thus leading to maximum elimination of brain tumors along with reduced adverse impact on functional outcomes.

Current supportive treatment primarily includes anticonvulsants and corticosteroids, focusing on relieving symptoms [7]. Corticosteroids can help manage side effects such as nausea, but may impact mood and memory [102]. No neurorehabilitative strategy is clinically available to protect the brain from treatment-related toxicity while also improving long-term neurological function. A limited number of studies have aimed to investigate regimens with neurorehabilitative effects. Ramipril, an inhibitor of angiotensin-converting enzyme (ACE), was shown to ameliorate radiation-induced brain damage in a rat optic neuropathy model [103]. A thrombin inhibitor was used in a rat glioma model to reduce tumor size while also providing functional benefit $[104,105]$. A preliminary, retrospective investigation in a sample of patients with primary malignant brain tumors demonstrated the effectiveness of postacute brain injury rehabilitation methods, originally developed for traumatic brain injury survivors, in ameliorating neurobehavioral deficits due to the tumor, surgical resection, and subsequent radiation and chemotherapy [106]

However, in addition to the dilemma that treatment regimens targeting tumor promotion pathways may depress neuroplasticity and functional recovery, the possibility that treatments able to protect and benefit injured neuronal tissue may also protect and benefit tumor tissue creates another dilemma confronting brain tumor management. Injured brain tissue can excrete factors promoting dendritic growth and functional recovery [107]. Fluid derived from wound injury was shown to accelerate growth of C6 glioma in spheroid culture, suggesting the stimulatory effect of injury on tumor progression [108]. Therefore, as a premise of any applicable value, the effects of neurorehabilitative treatments on tumor growth and regrowth should be cautiously investigated.

\section{Can Brain Repair and Tumor Suppression Possibly be Monitored in the Same Way?}

Brain repair and tumor suppression may not always be contradictory and can possibly be monitored in the same way. Malignant glioma cells attract endogenous precursor cells as a reparative mechanism and the presence of precursor cells is antitumorigenic [98-100]. Increased neuronal differentiation and synaptogenesis are associated with decreased aggressiveness in retinoblastoma [109]. Neurotrophins [Nerve growth factor (NGF), brain-derived neurotrophic factor (BDNF), and Neurotrophin 3 (NT-3)] are pivotal mediators of proliferation, differentiation, and survival of cells in the normal brain [110]. BDNF is widely established as a major trophic factor in the functioning of both normal and injured brains [55,111-114]. Human origin gliomas generate neurotrophins with BDNF being the most abundantly expressed, and extrinsic neurotrophins fail to stimulate mitosis of the glioma cultures [115]. There is evidence that neurotrophin signaling is involved in the process of apoptosis and neuronal differentiation in medulloblastomas $[116,59]$. Whereas in normal blood vessel angiopoietin (Ang) -1 expression exceeds Ang2 expression, the opposite is true in tumor blood vessels $[117,118]$. Blocking the stabilizing effect of Ang-1 on both preexisting and newly formed blood vessels by Ang-2 cooperates with VEGF to induce tumor blood vessel growth [119-122,117,118,123]. Therefore, normalization of the expression pattern of Ang-1, Ang-2 and their endothelial cell receptor Tie 2 may normalize the abnormal structure and function of tumor vasculature to make it more efficient for oxygen and anti-cancer drug delivery [124]. Interestingly, in addition to reducing vascular permeability and enhancing vascular stabilization and maturation $[125,126]$, Ang-1 can trigger the migration of immature neurons to the site of brain damage and promote functional recovery after stroke [127], thus linking the two processes of neurogenesis and angiogenesis together.

\section{Functional Assessment is Important in Translational Brain Tumor Research}

The main challenge facing modern brain cancer research is to develop novel interventions or improve existing treatments, to reduce undesirable neurological side effects while maintaining anti-cancer efficacy, as well as to design therapeutic regimens that can provide neuroprotection during cancer treatment or promote neurorestoration afterwards. In clinical trials, functional outcome is a major target, but seems to be neglected in translational brain tumor research. This might be accounted for by the assumption that the primary goal of a cancer treatment is to prolong life, and that reduction of tumor size may consequentially lead to functional improvement. Furthermore, it may also be the lack of suitable experimental approaches to assess functional outcomes, which, unfortunately, has placed a serious limitation on the ability to weigh the risks and benefits of new cancer therapies and to develop strategies to rehabilitate damaged functions. 


\section{Recent Research Progress in Behavioral Neuro- oncological Field}

Before functional assessment can be included in evaluating the efficacy of potential treatments, simple methods for measuring behavioral changes in animal tumor models should be established. Brain tumors growing into different locations cause different neurological deficits, and accordingly, require different behavioral testing methods in animal models. The staircase test, which is an assay to determine skilled paw-reaching ability, has been used to measure progressive focal neurological dysfunction following experimental implantation glioma into the striatum in rats [129]. A recent study showed significant average sensorimotor deficits in rats bearing 9L glioma implanted into the sensorimotor cortex, but only when tumor growth was extensive [101]. A case-by-case analysis of brain tumor volumes measured by magnetic resonance imaging (MRI) and corresponding behavioral performance revealed a significant correlation between tumor volume and magnitude of somatosensory asymmetry, indicating that the somatosensory asymmetry test is a useful tool for gauging the extent of tumor progression [101].

In the investigation of functional outcome after a novel antiangiogenesis regimen in nude mice implanted with U87 glioma into the sensorimotor cortex, the combination of antibodies against both VEGF receptor -1 and 2 reduced glioma growth and delayed the onset of significant sensorimotor deficits in tumor-harboring animals [129]. A reduction in tumor size may result in functional improvement in parallel, however, the effects of tumor reduction may mask the adverse effects of the treatment on the integrity of brain function.

A model that can hold tumor size constant independent of treatment may help more directly assess the potential detrimental effects of tumor growth inhibitors on brain plasticity. A technique of epidural implantation of a hemisphere-shaped plastic bead overlying the sensorimotor cortex has been used to isolate the compression characteristics of a brain tumor $[130,131,92]$. Rapid brain compression induced mild sensorimotor deficits shown in forelimb-use asymmetry test (cylinder test), somatosensory asymmetry test, foot-fault test, tapered ledged beam test, and vibrissae-evoked forelimb placing test, which depended on the location, magnitude and duration of the focal compression [92]. This model was then applied to examine the impact of some cancer interventions on the compressed brain. Longterm administration of the NMDA receptor antagonist MK801 did not change the recovery rate but caused a reinstatement of behavioral deficits after complete recovery from focal brain compression [81]. Local chemotherapy with 5FU exacerbated compression-induced functional deficits [50]. The mild lesion pattern and the resultant neuroplasticity in this mass compression model make it especially suitable for detecting the adverse effects of anti-cancer treatments on functional integrity of the brain. Taken together, use of both a tumor implantation model and a controlled-rate non-tumor compression/ decompression model may prove very useful in the investigation of optimal treatments.

\section{Perspectives}

A further investigation to develop a controlled-rate focal compression model is warranted for testing anti-cancer drugs that possess tumor-shrinking effects and thereby determining which drugs operate efficaciously along with reduced harm to the compressed brain and its plastic ability.

To show "proof of principle", the same anti-cancer therapy, administered at the same dosage, by the same route, and under the same schedule, in both the non-tumor compression model and the tumor implantation model, is needed to bridge these two treatment screening systems. An example of an anti-cancer treatment that can interfere with functional recovery in the non-tumor compression model but can slow tumor growth and concurrently delay the onset of significant functional deficits in the tumor implantation model, may better demonstrate the necessity of utilizing both models to screen for treatments that have both improved anti-cancer effects and reduced adverse effects on functional integrity of the brain.

Because the hippocampus may be affected both by the tumor and by certain anti-cancer treatments, the water maze test and other tests for cognitive function are necessary for the measurement of functional outcome [132].

It would be interesting to block some neuroplastic events, for examples, by injecting anti-VEGF, anti-BFGF, or by blocking their receptors, and then compare the behavioral responses of animals bearing tumors of similar size and location with or without treatment. This experiment would be aimed at investigating whether tumor-induced neuroplastic mechanisms contribute to behavioral compensation. Because the treatments that block neuroplasticity may also slow tumor growth, MRI would be needed to monitor tumor size and location, and the comparison should be made between treated and non-treated tumors of similar size while not considering tumor growth time.

It would also be intriguing to investigate whether behavioral lifestyles, for example, exercise, can affect glioma growth. Exercise can reduce the risk of breast cancer [133-135], significantly improve the quality of life outcome and physiological capacity of breast cancer survivors [134], prolong their survival [136], and is likely to prevent the recurrence of breast cancer [137]. Running alone or combined with caffeine guards against skin cancer in mice $[138,139]$. Also, motor enrichment and exercise have been shown to promote neuroplasticity and to rescue brain tissue from progressive degeneration in animal models of Parkinson's, Alzheimer's and other brain diseases [113,140].

Another important future research direction is to establish a brain injury model caused by cancer therapy with long-lasting behavioral deficits, and to examine whether neurorestorative strategies can promote functional recovery after treatment-induced brain damage. Such models may include aspiration lesion or stab wound lesions, designed to mimic as closely as possible certain aspects of tumor resection surgery and focal delivery of radiation to the normal brain. Neurorestorative strategies may include physical therapy, gene therapy, cell therapy, and neurorestorative agents such as erythropoietin, atorvastatin, and sildenafil [141-161]. Functional promotion effects should be established initially in the nontumor animal undergoing cancer therapies. The effects of the neurorestorative strategies on tumor growth and regrowth should be examined in the tumor-bearing animal with and without cancer therapies. Additional studies should explore potential integrative effects of combinations of cancer therapy and neurorestorative therapy in glioma-bearing animals. Functional outcome and survival time both should be included as outcome measures.

In summary, some recent research has started to fill the critical behavioral void in the early phases of translational brain tumor research. Longer term goals are to continue to develop models to facilitate functional assessment, to screen for optimal cancer treatment 
strategies with reduced harm to brain function, and to search for novel neurorestorative strategies to promote functional outcome following standard brain tumor treatments. An improved collaboration among scientists in the areas of behavioral neuroscience, experimental and clinical neuro-oncology, neurosurgery and neurology would be needed to find better ways to help patients attain maximum functional capacity and the highest possible quality of life.

\section{Acknowledgement}

Davis Phinney Foundation.

\section{References}

1. Greenlee RT, Murray T, Bolden S, Wingo PA (2000) Cancer statistics, 2000. CA Cancer J Clin 50: 7-33.

2. Walker MD, Green SB, Byar DP, Alexander E, Jr., Batzdorf U, et al. (1980) Randomized comparisons of radiotherapy and nitrosoureas for the treatment of malignant glioma after surgery. N Engl J Med 303: 1323-1329.

3. Walker MD, Strike TA, Sheline GE (1979) An analysis of dose-effect relationship in the radiotherapy of malignant gliomas. Int J Radiat Oncol Biol Phys 5: 17251731.

4. Mikkelsen T, Edvardsen K (1996) Invasiveness in nervous system tumors. In: Black PM, Loeffler JS, editors. Cancer of the Nervous System. Blackwell Scientific Publications Cambridge.

5. Osoba D, Aaronson NK, Muller M, Sneeuw K, Hsu MA, et al. (1997) Effect of neurological dysfunction on health-related quality of life in patients with highgrade glioma. J Neurooncol 34: 263-278.

6. Uhm JH, Yung WK (1999) Neurologic complications of cancer therapy. Curr Treat Options Neuro I 1: 428-437.

7. DeAngelis LM, Loeffler JS, Mamelak AN (2004) Primary brain tumors. In: Pazdur R, et al, editors. Cancer Management: A Multidisciplinary Approach: Medical, Surgical and Radiation Oncology. (8thedn), Oncology Publishing Group Manhasset, New York.

8. Bleehen NM, Stenning SP (1991) A Medical Research Council trial of two radiotherapy doses in the treatment of grades 3 and 4 astrocytoma. The Medical Research Council Brain Tumour Working Party. Br J Cancer 64: 769774 .

9. Hess CF, Schaaf JC, Kortmann RD, Schabet M, Bamberg M (1994) Malignant glioma: patterns of failure following individually tailored limited volume irradiation. Radiother Oncol 30: 146-149.

10. Hochberg FH, Pruitt A (1980) Assumptions in the radiotherapy of glioblastoma Neurology 30: 907-911.

11. Wallner KE, Galicich JH, Krol G, Arbit E, Malkin MG (1989) Patterns of failure following treatment for glioblastoma multiforme and anaplastic astrocytoma. Int J Radiat Oncol Biol Phys 16: 1405-1409.

12. Garden AS, Maor MH, Yung WK, Bruner JM, Woo SY, et al. (1991) Outcome and patterns of failure following limited-volume irradiation for malignant astrocytomas. Radiother Oncol 20: 99-110.

13. Lee SW, Fraass BA, Marsh LH, Herbort K, Gebarski SS, et al. (1999) Patterns of failure following high-dose 3-D conformal radiotherapy for high-grade astrocytomas: a quantitative dosimetric study. Int J Radiat Oncol Biol Phys 43: 79-88.

14. Fitzek MM, Thornton AF, Rabinov JD, Lev MH, Pardo FS, et al. (1999) Accelerated fractionated proton/photon irradiation to 90 cobalt gray equivalent for glioblastoma multiforme: results of a phase II prospective trial. J Neurosurg 91: $251-260$

15. Liebel SA, Sheline GE (1991) Tolerance of the brain and spinal cord to conventional irradiation. In: Gutin $\mathrm{PH}$, et al. editors. Radiation Injury to the Nervous System, Raven Press, New York.

16. Suit HD, Baumann M, Skates S, Convery K (1989) Clinical interest in determinations of cellular radiation sensitivity. Int J Radiat Biol 56: 725-737.

17. Duffner PK (2004) Long-term effects of radiation therapy on cognitive and endocrine function in children with leukemia and brain tumors. Neurologist 10: 293-310.

18. Schultheiss TE, Stephens LC, Peters LJ (1986) Survival in radiation myelopathy.
Int J Radiat Oncol Biol Phys 12: 1765-1769.

19. Soo EW, Galindo EG, Levin VA (1995) Brain tumors. In: Pazdur R, editors Medical Oncology: A Comprehensive Review. (2ndedn), Huntington, New York.

20. Vigliani MC, Duyckaerts C, Hauw JJ, Poisson M, Magdelenat H, et al. (1999) Dementia following treatment of brain tumors with radiotherapy administered alone or in combination with nitrosourea-based chemotherapy: a clinical and pathological study. J Neurooncol 41: 137-149.

21. Raber J, Fan Y, Matsumori Y, Liu Z, Weinstein PR, et al. (2004) Irradiation attenuates neurogenesis and exacerbates ischemia-induced deficits. Ann Neurol 55: 381-389.

22. Raber J, Rola R, LeFevour A, Morhardt D, Curley J, et al. (2004) Radiationinduced cognitive impairments are associated with changes in indicators of hippocampal neurogenesis. Radiat Res 162: 39-47.

23. Aarsen FK, Paquier PF, Reddingius RE, Streng IC, Arts WF, et al. (2006 Functional outcome after low-grade astrocytoma treatment in childhood. Cancer 106: 396-402.

24. Barbieux C, Patri B, Cerf I, de Parades V (1996) Acute cerebellar syndrome after treatment with 5-fluorouracil. Bull Cancer 83: 77-80.

25. Bofill JS, Chaves M, Moreno JA (2000) Fluorouracil-induced aphasia. Ann Pharmacother 34: 955.

26. Bygrave HA, Geh JI, Jani Y, Glynne-Jones R (1998) Neurological complications of 5-fluorouracil chemotherapy: case report and review of the literature. Clin Oncol (R Coll Radiol) 10: 334-336.

27. Elkiran ET, Altundag K, Beyazit Y, Guler N, Kars A (2004) Fluorouracilinduced neurotoxicity presenting with generalized tonic-clonic seizure. Ann Pharmacother 38: 2171.

28. Figueredo AT, Fawcet SE, Molloy DW, Dobranowski J, Paulseth JE (1995) Disabling encephalopathy during 5-fluorouracil and levamisole adjuvant therapy for resected colorectal cancer: a report of two cases. Cancer Invest 13: $608-611$.

29. Hook CC, Kimmel DW, Kvols LK, Scheithauer BW, Forsyth PA, et al (1992) Multifocal inflammatory leukoencephalopathy with 5-fluorouracil and levamisole. Ann Neurol 31: 262-267.

30. Pirzada NA, Ali, II, Dafer RM (2000) Fluorouracil-induced neurotoxicity. Ann Pharmacother 34: 35-38.

31. Ahles TA, Saykin AJ (2007) Candidate mechanisms for chemotherapy-induced cognitive changes. Nat Rev Cancer 7: 192-201.

32. Winocur G, Vardy J, Binns MA, Kerr L, Tannock I (2006) The effects of the anticancer drugs, methotrexate and 5-fluorouracil, on cognitive function in mice. Pharmacol Biochem Behav 85: 66-75.

33. Dietrich J, Han R, Yang Y, Mayer-Proschel M, Noble M (2006) CNS progenitor cells and oligodendrocytes are targets of chemotherapeutic agents in vitro and in vivo. J Biol 5: 22.

34. Magda D, Lepp C, Gerasimchuk N, Lee I, Sessler JL, et al. (2001) Redox cycling by motexafin gadolinium enhances cellular response to ionizing radiation by forming reactive oxygen species. Int J Radiat Oncol Biol Phys 51: 1025-1036.

35. Naumovski L, Ramos J, Sirisawad M, Chen J, Thiemann P, et al. (2005) Sapphyrins induce apoptosis in hematopoietic tumor-derived cell lines and show in vivo antitumor activity. Mol Cancer Ther 4: 968-976.

36. Naumovski L, Sirisawad M, Lecane P, Chen J, Ramos J, et al. (2006) Tumor localization and antitumor efficacy of novel sapphyrin compounds. Mol Cancer Ther 5: 2798-2805.

37. Sessler JL, Miller RA (2000) Texaphyrins: new drugs with diverse clinical applications in radiation and photodynamic therapy. Biochem Pharmacol 59 733-739.

38. Wang Z, Lecane PS, Thiemann P, Fan Q, Cortez C, et al. (2007) Synthesis and biologic properties of hydrophilic sapphyrins, a new class of tumor-selective inhibitors of gene expression. Mol Cancer 6: 9.

39. Wei WH, Fountain M, Magda D, Wang Z, Lecane P, et al. (2005) Gadolinium texaphyrin-methotrexate conjugates. Towards improved cancer chemotherapeutic agents. Org Biomol Chem 3: 3290-3296.

40. Levin VA, Edwards MS, Wara WM, Allen J, Ortega J, et al. (1984) 5-Fluorouraci and 1-(2-chloroethyl)-3-cyclohexyl-1-nitrosourea (CCNU) followed by 
hydroxyurea, misonidazole, and irradiation for brain stem gliomas: a pilot study of the Brain Tumor Research Center and the Childrens Cancer Group. Neurosurgery 14: 679-681.

41. Shapiro WR (1971) Studies on the chemotherapy of experimental brain tumors: evaluation of 1-(2-chloroethyl)-3-cyclohexyl-1-nitrosourea, vincristine, and 5-fluorouracil. J Natl Cancer Inst 46: 359-368.

42. Shapiro WR, Green SB, Burger PC, Selker RG, VanGilder JC, et al. (1992) A randomized comparison of intra-arterial versus intravenous $B C N U$, with or without intravenous 5-fluorouracil, for newly diagnosed patients with malignant glioma. J Neurosurg 76: 772-781.

43. Levin VA, Chadwick M, Little AD (1972) Distribution of 5-fluorouracil-2- 14 C and its metabolites in a murine glioma. J Natl Cancer Inst 49: 1577-1584.

44. Neuwelt EA, Barnett PA, Frenkel EP (1984) Chemotherapeutic agen permeability to normal brain and delivery to avian sarcoma virus-induced brain tumors in the rodent: observations on problems of drug delivery. Neurosurgery 14: $154-160$

45. Fournier E, Passirani C, Montero-Menei C, Colin N, Breton P, et al. (2003) Therapeutic effectiveness of novel 5-fluorouracil-loaded poly(methylidene malonate 2.1.2)-based microspheres on F98 glioma-bearing rats. Cancer 97: 2822-2829.

46. Lemaire L, Roullin VG, Franconi F, Venier-Julienne MC, Menei P, et al. (2001) Therapeutic efficacy of 5 -fluorouracil-loaded microspheres on rat glioma: a magnetic resonance imaging study. NMR Biomed 14: 360-366.

47. Menei P, Boisdron-Celle M, Croue A, Guy G, Benoit JP (1996) Effect of stereotactic implantation of biodegradable 5-fluorouracil-loaded microspheres in healthy and C6 glioma-bearing rats. Neurosurgery 39: 117-123.

48. Menei P, Jadaud E, Faisant N, Boisdron-Celle M, Michalak S, et al. (2004) Stereotaxic implantation of 5-fluorouracil-releasing microspheres in malignant glioma. Cancer 100: 405-410.

49. Noordhuis $P$, Holwerda U, Van der Wilt CL, Van Groeningen CJ, Smid K, et al. (2004) 5-Fluorouracil incorporation into RNA and DNA in relation to thymidylate synthase inhibition of human colorectal cancers. Ann Oncol 15: 1025-1032.

50. Yang H, Zhang X, Chopp M, Jiang F, Schallert T (2006) Local fluorouraci chemotherapy interferes with neural and behavioral recovery after brain tumorlike mass compression. Behav Brain Res 172: 80-89.

51. Mikkelsen T (1998) Cytostatic Agents in the Management of Malignant Gliomas. Cancer Control 5: 150-162

52. Chao JY, Wei L, Yin K, Lin TN, Hsu CY (2002) Angiogenesis after experimental cerebral ischemia-reperfusion. In: Krieglstein J, Klumpp $\mathrm{S}$, editors. Pharmacology of Cerebral Ischemia. Medpharm Scientific Publishers, Stuttgart.

53. Cramer SC, Chopp M (2000) Recovery recapitulates ontogeny. Trends Neurosci 23: 265-271.

54. Gomez-Pinilla F, Lee JW, Cotman CW (1992) Basic FGF in adult rat brain: cellular distribution and response to entorhinal lesion and fimbria-fornix transection. J Neurosci 12: 345-355

55. Keyvani K, Schallert T (2002) Plasticity-associated molecular and structural events in the injured brain. J Neuropathol Exp Neurol 61: 831-840.

56. Mattson MP, Culmsee C, Slevin JR, Liu D (2002) Synaptic apoptosis and neuroprotective strategies. In: Krieglstein J, Klumpp S, editors. Pharmacology of Cerebral Ischemia. Medpharm Scientific Publishers, Stuttgart.

57. Parent JM, Vexler ZS, Gong C, Derugin N, Ferriero DM (2002) Rat forebrain neurogenesis and striatal neuron replacement after focal stroke. Ann Neurol 52: $802-813$

58. Arrieta O, Guevara P, Escobar E, Garcia-Navarrete R, Pineda B, et al. (2005) Blockage of angiotensin II type I receptor decreases the synthesis of growth factors and induces apoptosis in $\mathrm{C} 6$ cultured cells and $\mathrm{C} 6$ rat glioma. $\mathrm{Br} \mathrm{J}$ Cancer 92: 1247-1252.

59. Eberhart CG, Kaufman WE, Tihan T, Burger PC (2001) Apoptosis, neuronal maturation, and neurotrophin expression within medulloblastoma nodules. J Neuropathol Exp Neurol 60: 462-469.

60. Kaur B, Khwaja FW, Severson EA, Matheny SL, Brat DJ, et al. (2005) Hypoxia and the hypoxia-inducible-factor pathway in glioma growth and angiogenesis. Neuro Oncol 7: 134-153.

61. Rege TA, Fears CY, Gladson CL (2005) Endogenous inhibitors of angiogenesis in malignant gliomas: nature's antiangiogenic therapy. Neuro Oncol 7: 106-121.

62. Singh SK, Clarke ID, Hide T, Dirks PB (2004) Cancer stem cells in nervous system tumors. Oncogene 23: 7267-7273

63. Kargiotis O, Rao JS, Kyritsis AP (2006) Mechanisms of angiogenesis in gliomas. J Neurooncol 78: 281-293.

64. Plate KH, Risau W (1995) Angiogenesis in malignant gliomas. Glia 15: 339 347.

65. Plate KH, Breier G, Millauer B, Ullrich A, Risau W (1993) Up-regulation of vascular endothelial growth factor and its cognate receptors in a rat glioma model of tumor angiogenesis. Cancer Res 53: 5822-5827.

66. Plate KH, Breier G, Weich HA, Mennel HD, Risau W (1994) Vascula endothelial growth factor and glioma angiogenesis: coordinate induction of VEGF receptors, distribution of VEGF protein and possible in vivo regulatory mechanisms. Int J Cancer 59: 520-529.

67. Plate KH, Breier G, Weich HA, Risau W (1992) Vascular endothelial growth factor is a potential tumour angiogenesis factor in human gliomas in vivo. Nature 359: 845-848.

68. Cheng SY, Huang HJ, Nagane M, Ji XD, Wang D, et al. (1996) Suppression of glioblastoma angiogenicity and tumorigenicity by inhibition of endogenous expression of vascular endothelial growth factor. Proc Natl Acad Sci U S A 93 8502-8507.

69. Kim KJ, Li B, Winer J, Armanini M, Gillett N, et al. (1993) Inhibition of vascular endothelial growth factor-induced angiogenesis suppresses tumour growth in vivo. Nature 362: 841-844

70. Krum JM, Khaibullina A (2003) Inhibition of endogenous VEGF impedes revascularization and astroglial proliferation: roles for VEGF in brain repair Exp Neurol 181: 241-257.

71. Auguste P, Gursel DB, Lemiere S, Reimers D, Cuevas P, et al. (2001) Inhibition of fibroblast growth factor/fibroblast growth factor receptor activity in glioma cells impedes tumor growth by both angiogenesis-dependent and -independent mechanisms. Cancer Res 61: 1717-1726.

72. Ke LD, Shi YX, Im SA, Chen X, Yung WK (2000) The relevance of cell proliferation, vascular endothelial growth factor, and basic fibroblast growth factor production to angiogenesis and tumorigenicity in human glioma cell lines. Clin Cancer Res 6: 2562-2572.

73. Segal DH, Germano IM, Bederson JB (1997) Effects of basic fibroblast growth factor on in vivo cerebral tumorigenesis in rats. Neurosurgery 40: 1027-1033.

74. Stan AC, Nemati MN, Pietsch T, Walter GF, Dietz H (1995) In vivo inhibition of angiogenesis and growth of the human U-87 malignant glial tumor by treatment with an antibody against basic fibroblast growth factor. J Neurosurg 82: 1044 1052.

75. Rowntree S, Kolb B (1997) Blockade of basic fibroblast growth factor retards recovery from motor cortex injury in rats. Eur J Neurosci 9: 2432-2441.

76. Kawamata T, Dietrich WD, Schallert T, Gotts JE, Cocke RR, et al. (1997) Intracisternal basic fibroblast growth factor enhances functional recovery and up-regulates the expression of a molecular marker of neuronal sprouting following focal cerebral infarction. Proc Natl Acad Sci U S A 94: 8179-8184.

77. Schallert T, Woodlee MT, Fleming SM (2003) Experimental focal ischemic injury: behavior-brain interactions and issues of animal handling and housing. llar J 44: 130-143.

78. Ishiuchi S, Tsuzuki K, Yoshida Y, Yamada N, Hagimura N, et al. (2002 Blockage of $\mathrm{Ca}^{(2+)}$-permeable AMPA receptors suppresses migration and induces apoptosis in human glioblastoma cells. Nat Med 8: 971-978.

79. Rzeski W, Turski L, Ikonomidou C (2001) Glutamate antagonists limit tumor growth. Proc Natl Acad Sci U S A 98: 6372-6377.

80. Takano T, Lin JH, Arcuino G, Gao Q, Yang J, et al. (2001) Glutamate release promotes growth of malignant gliomas. Nat Med 7: 1010-1015.

81. Yang H, Chopp M, Jiang F, Zhang X, Schallert $\mathrm{T}$ (2006) Interruption of functional recovery by the NMDA glutamate antagonist MK801 after compression of the sensorimotor cortex: implications for treatment of tumors or other mass-related brain injuries. Exp Neurol 200: 262-266.

82. Kozlowski DA, Jones TA, Schallert T (1994) Pruning of dendrites and restoration of function after brain damage: role of the NMDA receptor. Rest Neurol Neurosci 7: 119-126. 
83. Kadish I, Van Groen T (2003) Differences in lesion-induced hippocampal plasticity between mice and rats. Neuroscience 116: 499-509.

84. Kundrotiene J, Cebers G, Wagner A, Liljequist S (2004) The NMDA NR2B subunit-selective receptor antagonist, CP-101,606, enhances the functional recovery the NMDA NR2B subunit-selective receptor and reduces brain damage after cortical compression-induced brain ischemia. J Neurotrauma 21 83-93.

85. Kundrotiene J, Wagner A, Liljequist S (2002) Extradural compression of sensorimotor cortex: a useful model for studies on ischemic brain damage and neuroprotection. J Neurotrauma 19: 69-84.

86. Moreira T, Cebers G, Cebere A, Wagner A, Liljequist S (2005) Extradural compression of the sensorimotor cortex delays the acquisition but not the recalling of a lever-pressing task in Wistar rats. Behav Brain Res 164: 250-265.

87. Moreira T, Cebers G, Pickering C, Ostenson CG, Efendic S, et al. (2007) Diabetic Goto-Kakizaki rats display pronounced hyperglycemia and longerlasting cognitive impairments following ischemia induced by cortical compression. Neuroscience 144: 1169-1185.

88. Moreira T, Cebers G, Salehi M, Wagner A, Liljequist S (2006) Impaired long-term habituation is dissociated from increased locomotor activity after sensorimotor cortex compression. Behav Brain Res 167: 9-22.

89. Pollard H, Khrestchatisky M, Moreau J, Ben-Ari Y, Represa A (1994) Correlation between reactive sprouting and microtubule protein expression in epileptic hippocampus. Neuroscience 61: 773-787.

90. Stroemer RP, Kent TA, Hulsebosch CE (1992) Increase in synaptophysin immunoreactivity following cortical infarction. Neurosci Lett 147: 21-24.

91. Stroemer RP, Kent TA, Hulsebosch CE (1993) Acute increase in expression of growth associated protein GAP-43 following cortical ischemia in rat. Neurosci Lett 162: 51-54.

92. Yang H, Preston M, Chopp M, Jiang F, Zhang X, et al. (2006) Mass-related traumatic tissue displacement and behavior: a screen for treatments that reduce [corrected] harm to bystander cells and recovery of function. J Neurotrauma 23 721-732.

93. Zhang R, Zhang Z, Wang L, Wang Y, Gousev A, et al. (2004) Activated neura stem cells contribute to stroke-induced neurogenesis and neuroblast migration toward the infarct boundary in adult rats. J Cereb Blood Flow Metab 24: 441 448.

94. Zhang R, Zhang Z, Zhang C, Zhang L, Robin A, et al. (2004) Stroke transiently increases subventricular zone cell division from asymmetric to symmetric and increases neuronal differentiation in the adult rat. J Neurosci 24: 5810-5815.

95. Zhang RL, LeTourneau Y, Gregg SR, Wang Y, Toh Y, et al. (2007) Neuroblas division during migration toward the ischemic striatum: a study of dynamic migratory and proliferative characteristics of neuroblasts from the subventricular zone. J Neurosci 27: 3157-3162.

96. Zhang RL, Zhang ZG, Wang Y, Letourneau Y, Liu XS, et al. (2007) Stroke induces ependymal cell transformation into radial glia in the subventricular zone of the adult rodent brain. J Cereb Blood Flow Metab 27: 1201-1212.

97. Fleming SM, Delville Y, Schallert T (2005) An intermittent, controlled-rate, slow progressive degeneration model of Parkinson's disease: antiparkinson effects of Sinemet and protective effects of methylphenidate. Behav Brain Res 156: 201-213.

98. Bexell D, Gunnarsson S, Nordquist J, Bengzon J (2007) Characterization of the subventricular zone neurogenic response to rat malignant brain tumors. Neuroscience 147: 824-832.

99. Duntsch C, Zhou Q, Weimar JD, Frankel B, Robertson JH, et al. (2005) Up-regulation of neuropoiesis generating glial progenitors that infiltrate rat intracranial glioma. J Neurooncol 71: 245-255

100. Glass R, Synowitz M, Kronenberg G, Walzlein JH, Markovic DS, et al. (2005) Glioblastoma-induced attraction of endogenous neural precursor cells is associated with improved survival. J Neurosci 25: 2637-2646.

101. Yang H, Chopp M, Weiland B, Zhang X, Tepley N, et al. (2007) Sensorimotor deficits associated with brain tumor progression and tumor-induced brain plasticity mechanisms. Exp Neurol 207: 357-367.

102. Hukovic N, Brown ES (2003) Effects of prescription corticosteroids on mood and memory. Adv Psychosom Med 24: 161-167.

103. Kim JH, Brown SL, Kolozsvary A, Jenrow KA, Ryu S, et al. (2004) Modification of radiation injury by ramipril, inhibitor of angiotensin-converting enzyme, on optic neuropathy in the rat. Radiat Res 161: 137-142.

104. Hua Y, Tang L, Keep RF, Schallert T, Fewel ME, et al. (2005) The role of thrombin in gliomas. J Thromb Haemost 3: 1917-1923.

105. Hua Y, Tang LL, Fewel ME, Keep RF, Schallert T, et al. (2005) Systemic use of argatroban reduces tumor mass, attenuates neurological deficits and prolongs survival time in rat glioma models. Acta Neurochir Suppl 95: 403-406.

106. Sherer M, Meyers CA, Bergloff P (1997) Efficacy of postacute brain injury rehabilitation for patients with primary malignant brain tumors. Cancer 80: 250257.

107. Voorhies AC, Jones TA (2002) The behavioral and dendritic growth effects of focal sensorimotor cortical damage depend on the method of lesion induction. Behav Brain Res 133: 237-246.

108. Abramovitch R, Marikovsky M, Meir G, Neeman M (1999) Stimulation of tumour growth by wound-derived growth factors. Br J Cancer 79: 1392-1398.

109. Johnson DA, Zhang J, Frase S, Wilson M, Rodriguez-Galindo C (2007) Neuronal differentiation and synaptogenesis in retinoblastoma. Cancer Res 67: 2701-2711.

110. Ibanez CF, Hokfelt T, Olson L, Fuxe K, Jornvall H, et al. (1995) Life and Death in the Nervous System: Role of Neurotrophic Factors and their Receptors. Elsevier Science Pub Co, New York.

111. Kim MW, Bang MS, Han TR, Ko YJ, Yoon BW, et al. (2005) Exercise increased BDNF and trkB in the contralateral hemisphere of the ischemic rat brain. Brain Res 1052: 16-21.

112. Kleim JA, Chan S, Pringle E, Schallert K, Procaccio V, et al. (2006) BDNF val66met polymorphism is associated with modified experience-dependent plasticity in human motor cortex. Nat Neurosci 9: 735-737.

113. Kleim JA, Jones TA, Schallert T (2003) Motor enrichment and the induction of plasticity before or after brain injury. Neurochem Res 28: 1757-1769.

114. Vaynman S, Ying Z, Gomez-Pinilla F (2004) Hippocampal BDNF mediates the efficacy of exercise on synaptic plasticity and cognition. Eur $\mathrm{J}$ Neurosci 20: $2580-2590$

115. Hamel W, Westphal M, Szonyi E, Escandon E, Nikolics K (1993) Neurotrophin gene expression by cell lines derived from human gliomas. J Neurosci Res 34: 147-157.

116. Chou TT, Trojanowski JQ, Lee VM (1997) Neurotrophin signal transduction in medulloblastoma. J Neurosci Res 49: 522-527.

117. Stratmann A, Risau W, Plate KH (1998) Cell type-specific expression of angiopoietin-1 and angiopoietin-2 suggests a role in glioblastoma angiogenesis. Am J Pathol 153: 1459-1466

118. Tse V, Xu L, Yung YC, Santarelli JG, Juan D, et al. (2003) The temporalspatial expression of VEGF, angiopoietins-1 and 2, and Tie-2 during tumo angiogenesis and their functional correlation with tumor neovascular architecture. Neurol Res 25: 729-738.

119. Audero E, Cascone I, Zanon I, Previtali SC, Piva R, et al. (2001) Expression of angiopoietin-1 in human glioblastomas regulates tumor-induced angiogenesis: in vivo and in vitro studies. Arterioscler Thromb Vasc Biol 21: 536-541.

120.Ding H, Roncari L, Wu X, Lau N, Shannon P, et al. (2001) Expression and hypoxic regulation of angiopoietins in human astrocytomas. Neuro Oncol 3 : $1-10$

121. Holash J, Maisonpierre PC, Compton D, Boland P, Alexander CR, et al. (1999) Vessel cooption, regression, and growth in tumors mediated by angiopoietins and VEGF. Science 284: 1994-1998.

122. Papetti M, Herman IM (2002) Mechanisms of normal and tumor-derived angiogenesis. Am J Physiol Cell Physiol 282: C947-970.

123.Zagzag D, Hooper A, Friedlander DR, Chan W, Holash J, et al. (1999) In situ expression of angiopoietins in astrocytomas identifies angiopoietin-2 as an early marker of tumor angiogenesis. Exp Neurol 159: 391-400.

124. Jain RK (2005) Normalization of tumor vasculature: an emerging concept in antiangiogenic therapy. Science 307: 58-62.

125. Suri C, Jones PF, Patan S, Bartunkova S, Maisonpierre PC, et al. (1996) Requisite role of angiopoietin-1, a ligand for the TIE2 receptor, during embryonic angiogenesis. Cell 87: 1171-1180. 
126. Suri C, McClain J, Thurston G, McDonald DM, Zhou H, et al. (1998) Increased vascularization in mice overexpressing angiopoietin-1. Science 282: 468-471.

127. Ohab JJ, Fleming SM, Blesch A, Carmichael ST (2006) A neurovascular niche for neurogenesis after stroke. J Neurosci 26: 13007-13016.

128. Whittle IR, Marston HM (1997) Progressive focal neurological dysfunction following experimental implantation glioma. Neuroreport 8: 1149-1153.

129. Yang H, Chopp M, Zhang X, Jiang F, Zhang Z, et al. (2007) Using behavioral measurement to assess tumor progression and functional outcome after antiangiogenic treatment in mouse glioma models. Behav Brain Res 182: 42 50.

130. Chen JR, Wang YJ, Tseng GF (2003) The effect of epidural compression on cerebral cortex: a rat model. J Neurotrauma 20: 767-780.

131.Chen JR, Wang YJ, Tseng GF (2004) The effects of decompression and exogenous NGF on compressed cerebral cortex. J Neurotrauma 21: 16401651.

132. Schallert T (2006) Behavioral tests for preclinical intervention assessment. NeuroRx 3: 497-504.

133. Bernstein L, Patel AV, Ursin G, Sullivan-Halley J, Press MF, et al. (2005) Lifetime recreational exercise activity and breast cancer risk among black women and white women. J Natl Cancer Inst 97: 1671-1679.

134. Hewitt JA, Mokbel K, van Someren KA, Jewell AP, Garrod R (2005) Exercise for breast cancer survival: the effect on cancer risk and cancer-related fatigue (CRF). Int J Fertil Womens Med 50: 231-239.

135. Tehard B, Friedenreich CM, Oppert JM, Clavel-Chapelon F (2006) Effect of physical activity on women at increased risk of breast cancer: results from the E3N cohort study. Cancer Epidemiol Biomarkers Prev 15: 57-64.

136. Holmes MD, Chen WY, Feskanich D, Kroenke CH, Colditz GA (2005) Physica activity and survival after breast cancer diagnosis. JAMA 293: 2479-2486.

137. Hann D, Baker F, Denniston M, Entrekin N (2005) Long-term breast cancer survivors' use of complementary therapies: perceived impact on recovery and prevention of recurrence. Integr Cancer Ther 4: 14-20.

138. Lu YP, Nolan B, Lou YR, Peng QY, Wagner GC, et al. (2007) Voluntary exercise together with oral caffeine markedly stimulates UVB light-induced apoptosis and decreases tissue fat in SKH-1 mice. Proc Natl Acad Sci U S A 104: 12936-12941.

139. Michna L, Wagner GC, Lou YR, Xie JG, Peng QY, et al. (2006) Inhibitory effects of voluntary running wheel exercise on UVB-induced skin carcinogenesis in SKH-1 mice. Carcinogenesis 27: 2108-2115.

140. Woodlee MT, Schallert T (2006) The impact of motor activity and inactivity on the brain: implications for the prevention and treatment of nervous system disorders. Curr Direct Psychol Sci 15: 203-206.

141. Chen J, Chopp M (2006) Neurorestorative treatment of stroke: cell and pharmacological approaches. NeuroRx 3: 466-473.

142. Chen J, Zhang C, Jiang H, Li Y, Zhang L, et al. (2005) Atorvastatin induction of VEGF and BDNF promotes brain plasticity after stroke in mice. J Cereb Blood Flow Metab 25: 281-290.

143. Chen J, Zhang ZG, Li Y, Wang Y, Wang L, et al. (2003) Statins induce angiogenesis, neurogenesis, and synaptogenesis after stroke. Ann Neurol 53: 743-751.

144. Chopp M, Li Y (2006) Transplantation of bone marrow stromal cells for treatment of central nervous system diseases. Adv Exp Med Biol 585: 49-64.

145. Liu Y, Dulchavsky DS, Gao X, Kwon D, Chopp M, et al. (2006) Wound repair by bone marrow stromal cells through growth factor production. J Surg Res136: 336-341.

146. Lu D, Goussev A, Chen J, Pannu P, Li Y, et al. (2004) Atorvastatin reduces neurological deficit and increases synaptogenesis, angiogenesis, and neuronal survival in rats subjected to traumatic brain injury. $J$ Neurotrauma 21: $21-32$

147.Lu D, Mahmood A, Goussev A, Qu C, Zhang ZG, et al. (2004) Delayed thrombosis after traumatic brain injury in rats. J Neurotrauma 21: 1756-1766.

148. Lu D, Mahmood A, Goussev A, Schallert T, Qu C, et al. (2004) Atorvastatin reduction of intravascular thrombosis, increase in cerebral microvascular patency and integrity, and enhancement of spatial learning in rats subjected to traumatic brain injury. J Neurosurg 101: 813-821.

149. Lu D, Mahmood A, Qu C, Goussev A, Lu M, et al. (2004) Atorvastatin reduction of intracranial hematoma volume in rats subjected to controlled cortical impact. J Neurosurg 101: 822-825

150. Mahmood A, Lu D, Qu C, Goussev A, Chopp M (2006) Long-term recovery after bone marrow stromal cell treatment of traumatic brain injury in rats. $J$ Neurosurg 104: 272-277.

151. Mahmood A, Lu D, Qu C, Goussev A, Chopp M (2007) Treatment of traumatic brain injury with a combination therapy of marrow stromal cells and atorvastatin in rats. Neurosurgery 60: 546-553.

152. Mahmood A, Lu D, Qu C, Goussev A, Zhang ZG, et al. (2007) Treatment of traumatic brain injury in rats with erythropoietin and carbamylated erythropoietin. J Neurosurg 107: 392-397.

153. McFarlin K, Gao X, Liu YB, Dulchavsky DS, Kwon D, et al. (2006) Bone marrow-derived mesenchymal stromal cells accelerate wound healing in the rat. Wound Repair Regen 14: 471-478.

154. Seyfried D, Ding J, Han Y, Li Y, Chen J, et al. (2006) Effects of intravenous administration of human bone marrow stromal cells after intracerebral hemorrhage in rats. J Neurosurg 104: 313-318.

155. Seyfried D, Han Y, Lu D, Chen J, Bydon A, et al. (2004) Improvement in neurological outcome after administration of atorvastatin following experimental intracerebral hemorrhage in rats. J Neurosurg 101: 104-107.

156. Shen LH, Li Y, Chen J, Cui Y, Zhang C, et al. (2007) One-year follow-up afte bone marrow stromal cell treatment in middle-aged female rats with stroke. Stroke 38: 2150-2156.

157. Shen LH, Li Y, Chen J, Zacharek A, Gao Q, et al. (2007) Therapeutic benefit of bone marrow stromal cells administered 1 month after stroke. J Cereb Blood Flow Metab 27: 6-13.

158. Wang Y, Zhang ZG, Rhodes K, Renzi M, Zhang RL, et al. (2007) Postischemic treatment with erythropoietin or carbamylated erythropoietin reduces infarction and improves neurological outcome in a rat model of focal cerebra ischemia. Br J Pharmacol 151: 1377-1384.

159.Zhang L, Zhang RL, Wang Y, Zhang C, Zhang ZG, et al. (2005) Functiona recovery in aged and young rats after embolic stroke: treatment with a phosphodiesterase type 5 inhibitor. Stroke 36: 847-852.

160.Zhang R, Wang Y, Zhang L, Zhang Z, Tsang W, et al. (2002) Sildenafil (Viagra) induces neurogenesis and promotes functional recovery after stroke in rats. Stroke 33: $2675-2680$.

161.Zhang RL, Zhang Z, Zhang L, Wang Y, Zhang C, et al. (2006) Delayed treatment with sildenafil enhances neurogenesis and improves functional recovery in aged rats after focal cerebral ischemia. J Neurosci Res 83: 12131219

162. Chopp M, Dereski MO, Madigan L, Jiang F, Logie B (1996) Sensitivity of 9L gliosarcomas to photodynamic therapy. Radiat Res 146: 461-465.

163. Chopp M, Madigan L, Dereski M, Jiang F, Li Y (1996) Photodynamic therapy of human glioma (U87) in the nude rat. Photochem Photobiol 64: 707-711.

164. Jiang F, Lilge L, Belcuig M, Singh G, Grenier J, et al. (1998) Photodynamic therapy using Photofrin in combination with buthionine sulfoximine (BSO) to treat $9 \mathrm{~L}$ gliosarcoma in rat brain. Lasers Surg Med 23: 161-166.

165. Jiang F, Lilge L, Logie B, Li Y, Chopp M (1997) Photodynamic therapy of 9L gliosarcoma with liposome-delivered photofrin. Photochem Photobiol 65 701-706.

166. Plotkin SR, Wen PY (2003) Neurologic complications of cancer therapy Neurol Clin 21: 279-318

167.Ross BD, Zhao YJ, Neal ER, Stegman LD, Ercolani M, et al. (1998) Contributions of cell kill and posttreatment tumor growth rates to the repopulation of intracerebral 9L tumors after chemotherapy: an MRI study. Proc Natl Acad Sci U S A 95: 7012-7017.

168. Schepkin VD, Lee KC, Kuszpit K, Muthuswami M, Johnson TD, et al. (2006) Proton and sodium MRI assessment of emerging tumor chemotherapeutic resistance. NMR Biomed 19: 1035-1042.

169. Schepkin VD, Ross BD, Chenevert TL, Rehemtulla A, Sharma S, et al. (2005) Sodium magnetic resonance imaging of chemotherapeutic response in a rat glioma. Magn Reson Med 53: 85-92. 